\title{
Undetectable urinary free cortisol concentrations in a case of Cushing's disease
}

\author{
B G Issa ${ }^{1}$, M D Page ${ }^{4}$, G Read $^{2}$, R John ${ }^{2}$, A Douglas-Jones ${ }^{3}$ and M F Scanlon ${ }^{1}$ \\ Departments of ${ }^{1}$ Medicine, ${ }^{2}$ Medical Biochemistry and ${ }^{3}$ Histopathology, University Hospital of Wales, Cardiff and ${ }^{4}$ Department of Medicine, \\ East Glamorgan General Hospital, Pontypridd, UK
}

(Correspondence should be addressed to M F Scanlon, Department of Endocrinology, University Hospital of Wales, Heath Park, Cardiff CF4 4XN, UK)

\begin{abstract}
Measurement of the 24-h urinary free cortisol is a valuable screening test of endogenous hypercortisolism and, although false positive results may occur in a few situations, for example endogenous depression, false negative results are unusual. We report a case of a 48-year-old lady with pituitarydependent Cushing's disease, whose 24-h urinary free cortisol excretion was consistently undetectable in association with increased plasma and salivary cortisol concentrations and reduced dexamethasone suppressibility. The patient had chronic renal impairment (creatinine clearance $21 \mathrm{ml} / \mathrm{min}$ ) as a consequence of hypertension, despite only modestly increased urea and creatinine concentrations. Urinary free cortisol measurements must be interpreted with caution in patients with renal impairment.
\end{abstract}

European Journal of Endocrinology 140 148-151

\section{Introduction}

Several modifications in the methodology of measuring urinary free cortisol (UFC) have been introduced since it was first proposed as a test of adrenal function (1). At present, it is considered the best screening test of endogenous hypercortisolism, assuming complete collection of urine (2). The test has superseded measurements of the excretion of 17-hydroxycorticosteroids and 17-ketogenic steroids, which are dependent on body weight (3) and creatinine clearance, and are less sensitive $(4,5)$ than measurements of UFC. In addition, UFC excretion is relatively simple to measure in the laboratory.

Conditions that may lead to false positive UFC are well recognised by most endocrinologists and physicians. However, the causes of false negative UFC measurements are not clearly identified in the literature and the incidence varies between 'virtually absent' (2) to 36\% (6). Studies that have demonstrated high false negative rates for UFC assay were all conducted in the late 1950s and '60s; since then, the sensitivity and specificity of the UFC assay have improved considerably. The effects of renal impairment on UFC are variable and reduction of UFC excretion in Cushing's syndrome has been shown mostly only in severe renal impairment (creatinine clearance $<20 \mathrm{ml} / \mathrm{min}$ ) (7). We report a case of Cushing's disease and moderately severe renal impairment with undetectable UFC concentrations.

\section{Case report}

A 48-year-old lady presented to her local hospital with dyspnoea caused by congestive cardiac failure (CCF) and uncontrolled hypertension. There was no significant past history, apart from peptic ulceration 20 years previously. In particular, there was no history of steroid treatment or alcohol misuse. Examination revealed an increased blood pressure of 190/130 mmHg and signs of biventricular failure. The patient was noted to be Cushingoid, with a 'moon face', central adiposity and slight proximal muscle weakness. There was no evidence of a 'buffalo hump', supraclavicular fat pads, ecchymosis, abdominal striae or hirsutism. She had noticed a change in her facial appearance and easy bruising over the past 3 years and had been amenorrhoeic for 1 year before presentation. Her CCF and hypertension partially improved with frusemide, lisinopril and long-acting nifedipine. Plasma electrolytes, liver function tests and full blood count were normal, but the patient had increased urea and creatinine concentrations $(10 \mathrm{mmol} / \mathrm{l}$ and $220 \mathrm{~mol} / \mathrm{l}$ respectively). The electrocardiogram was normal. There was loss of diurnal rhythm for cortisol and adrenocorticotrophic hormone (ACTH), and failure of cortisol suppression with low-dose $(0.5 \mathrm{mg} 6$ hourly for $48 \mathrm{~h})$, but not high-dose ( $2 \mathrm{mg} 6$ hourly for $48 \mathrm{~h}$ ) dexamethasone. A computed tomography (CT) scan of the pituitary gland was normal, but adrenal CT revealed bilateral adrenal 
Table 1 Summary of baseline and dynamic tests of adrenal function.

\begin{tabular}{|c|c|c|c|c|c|c|c|}
\hline & \multicolumn{2}{|c|}{ Cortisol (nmol/l) } & \multicolumn{2}{|c|}{ ACTH $(\mathrm{ng} / \mathrm{l})$} & \multicolumn{2}{|c|}{ Salivary cortisol $(\mathrm{nmol} / \mathrm{l})$} & \multirow{2}{*}{$\begin{array}{c}\text { UFC } \\
(\mathrm{nmol} / 24 \mathrm{~h})\end{array}$} \\
\hline & $0900 \mathrm{~h}$ & $2400 \mathrm{~h}$ & $0900 \mathrm{~h}$ & $2400 \mathrm{~h}$ & $0900 \mathrm{~h}$ & $2400 h$ & \\
\hline Basal & 498 & 502 & 84.1 & 74 & & & $<28$ \\
\hline Basal & 559 & 504 & 84.3 & 53.4 & 32.4 & 21.6 & 50 \\
\hline Basal & 646 & 510 & 86.8 & 76.6 & 41.2 & 20.8 & $<28$ \\
\hline Low Dex, Day 1 & 453 & & & & 18 & & $<28$ \\
\hline Low Dex, Day 2 & 254 & & & & 7.6 & & $<28$ \\
\hline High Dex, Day 1 & 130 & & & & 2.9 & & $<28$ \\
\hline High Dex, Day 2 & $<28$ & & & & 0.9 & & $<28$ \\
\hline
\end{tabular}

Dex, dexamethasone.

hyperplasia. Throughout these investigations, 24-h UFC concentrations were low normal or undetectable $(<28 \mathrm{nmol} / 24 \mathrm{~h})$. Concomitant salivary cortisol concentrations were increased and failed to suppress with low-dose dexamethasone, consistent with the view that the undetectable UFC concentrations were misleading. The results of the biochemical investigations are summarised in Table 1. In view of the increased serum urea and creatinine concentrations, we suspected renal failure as the cause of low UFC. Creatinine clearance was reduced to $21 \mathrm{ml} / \mathrm{min}$, but ultrasound scan of the renal tract was unremarkable. MRI of the pituitary gland showed a 5-mm focal non-enhancing lesion in the left side of the pituitary fossa, consistent with an adenoma (Fig. 1). A diagnosis of pituitary-dependent Cushing's syndrome was made and the patient underwent selective transsphenoidal removal of a pituitary adenoma. Histology confirmed a pituitary microadenoma staining for immunoreactive ACTH (Fig. 2). Postoperative assessment showed suppression of 0900-h cortisol to less than $28 \mathrm{nmol} / \mathrm{l}$ with $1 \mathrm{mg}$ dexamethasone, with normal pituitary function otherwise indicating cure of her Cushing's disease. The 24-h UFC remained undetectable. Serum cortisol binding globulin (CBG) was within the normal range, at $300 \mathrm{nmol} / \mathrm{l}$ (normal range 290-420 nmol/l). Antihypertensive medication was withdrawn, with the blood pressure remaining in the normal range. There was regression of some of the clinical features of Cushing's syndrome.

\section{Methods}

Serum and urinary cortisol were measured by a competitive chemiluminescent immunoassay (Chiron Diagnostics, East Walpole, MA, USA) on an ACS-180 automated immunoassay analyser (Chiron Diagnostics). The method for measurement of UFC involved a prior extraction step of the urine with dichloromethane. UFC was also measured using an in-house extraction radioimmunoassay, confirming the UFC results obtained by the first technique. ACTH was measured by a two-site chemiluminometric assay (Nichols Institute, San Juan Capistrano, CA, USA).

\section{Discussion}

UFC represents the plasma protein unbound fraction of cortisol that is produced by ultrafiltration at the glomerulus after reabsorption of most (95\%) of the filtered load. Measured by HPLC or radioimmunoassay, it is considered the best screening test for hypercortisolism $(7,8)$. Our patient had low or undetectable UFC concentrations, despite increased plasma and salivary cortisol concentrations secondary to an ACTH-producing pituitary adenoma. The probable explanation for this discrepancy is the effect of renal impairment on cortisol filtration by the kidney. West (9) confirmed the findings of Gilliland \& Phillips (10), who demonstrated a clear correlation between UFC and creatinine clearance in 28 consecutive urine samples, but found normal or increased UFC in another group of patients with renal failure. In contrast, Ogunlesi et al. (11) found the concentrations of 24-h UFC excretion in 10 uraemic subjects (creatinine clearance $<30 \mathrm{ml} / \mathrm{min}$, fixed urine specific gravity and bilaterally shrunken kidneys on ultrasonography) to be significantly greater than those in nine controls. This was in association with loss of the circadian rhythm for cortisol secretion and failure of serum cortisol to be suppressed in response to dexamethasone (1 mg).

Renal failure may affect cortisol metabolism in various ways, including alteration in the hypothalamopituitary-adrenal axis (12), a prolonged half-life of serum cortisol (13) and decreased oxidation of tetrahydrocortisone to tetrahydrocortisol (14). However, this marked effect of renal impairment on UFC excretion is not widely appreciated, and this, together with abnormal cortisol binding, metabolite interference with assays for serum cortisol and poor absorption of dexamethasone from the gastrointestinal tract of patients with renal failure, may lead to obvious diagnostic difficulties.

Several investigators have suggested measuring alternative cortisol metabolites in the urine of patients with Cushing's syndrome to be a superior predictor of hypercortisolism than measurement of UFC (15-17). 

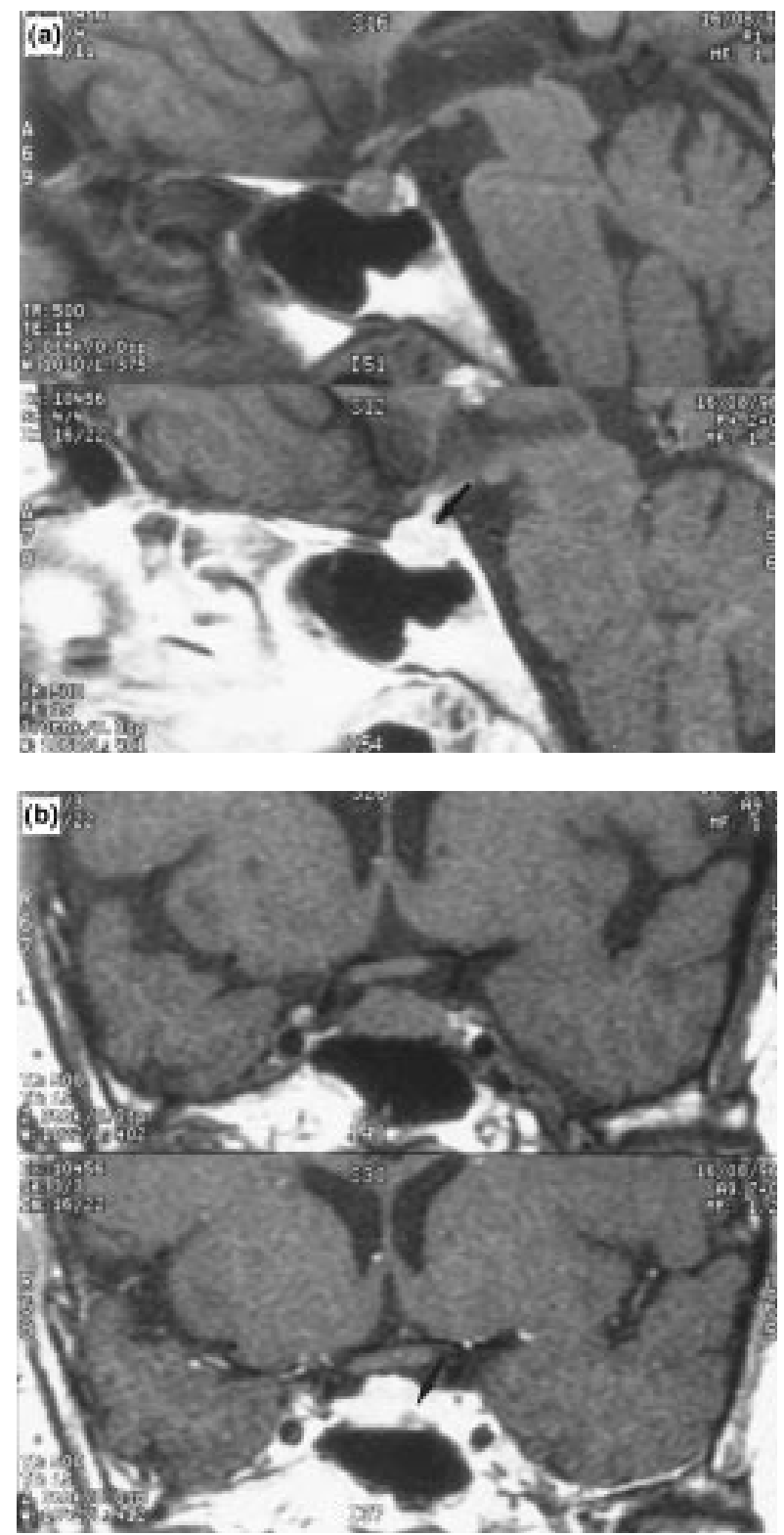

Figure $1(\mathrm{a}, \mathrm{b})$ Coronal and sagittal T1-weighted pre- and post-gadolinium pituitary MRI scans showing a $5-\mathrm{mm}$ non-enhancing lesion (arrow) consistent with a pituitary microadenoma.

Voccia et al. (17) studied 10 children with Cushing's syndrome and found that concentrations of urinary $6 \beta$-hydroxycortisol excretion were a better test for hypercortisolism than was UFC or 17-hydroxycorticosteroids. In 40 patients with pathologically proven Cushing's syndrome due to different causes, $20 \alpha$ dihydrocortisol was found to be a better index of hypercortisolism than was UFC $(15,16)$. Despite these observations, UFC remains the standard screening test for hypercortisolism in most laboratories. Because
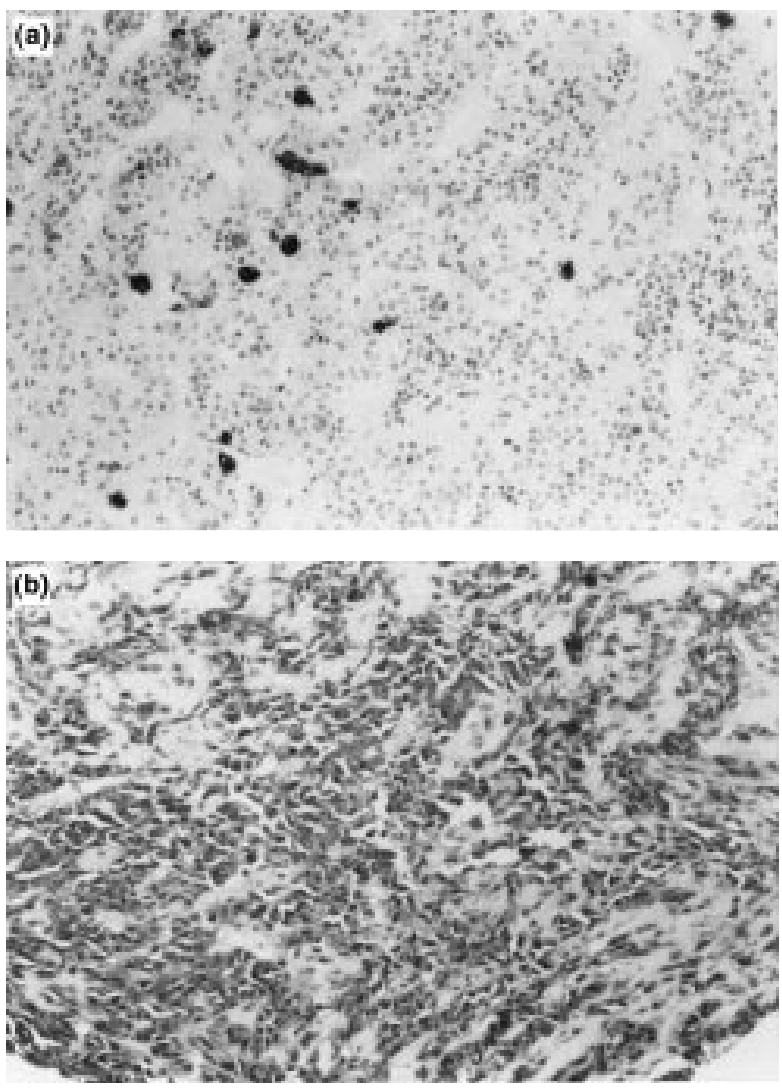

Figure 2 Immunostaining for ACTH. (a) Background (non-adenomatous) pituitary tissue showing normal staining Compare with sections through microadenoma (b), showing marked immunostaining for ACTH.

Cushing's syndrome is usually associated with hypertension and possible alterations in renal function, it is imperative to recognise and, if possible, study further the relationship between the degree of renal impairment and excretion of UFC. Despite the known regulatory effects of $\mathrm{CBG}$ on plasma cortisol transport and clearance (18), serum CBG concentrations in our patient were normal. Finally, the diagnosis of cyclical Cushing's disease was considered in our patient, but was believed to be unlikely, as UFC concentrations remained undetectable on many occasions and concommitant plasma and salivary cortisol concentrations were increased.

In conclusion, we report a patient with Cushing's disease and moderately severe renal failure with persistently low or undetectable UFC concentrations. Further studies should investigate the effect of various degrees of renal impairment on UFC. Clinicians should be aware that UFC measurements can be unreliable in patients with renal impairment, which limits the value of this test in screening for hypercortisolism in such patients. 


\section{Acknowledgements}

We would like to thank Mr Colin Selby, Department of Clinical Chemistry, City Hospital, Nottingham for performing the cortisol-binding globulin assay.

\section{References}

1 Cope CL \& Black EG. Urinary cortisol measurement in adrenocortical hyperfunction. British Medical Journal 19592 1117-1119.

2 Tigos C, Papanicolaou DA \& Chrousos GP. Advances in the diagnoses and treatment of Cushing's syndrome. Bailliere's Clinical Endocrinology and Metabolism 19959 315-336.

3 Streeten DHP, Stevenson CT, Dalakos TG, Nicholas JJ, Dennick LG \& Fellerman H. Diagnosis of hypercortisolism. Biochemical criteria of differentiating patients from lean and obese normal subjects and females on oral contraceptives. Journal of Clinical Endocrinology and Metabolism 196929 191-211.

4 Murphy BEP. Clinical evaluation of urinary cortisol determination by competitive protein binding radioassay. Journal of Clinical Endocrinology and Metabolism 196828 343-348.

5 Mattingly D \& Tyler C. Simple screening tests for Cushing's syndrome. British Medical Journal 19674 394-397.

6 Streeten DHP, Dalakos TG \& Anderson Jr GH. Diagnosis and treatment of Cushing's syndrome. In New Concepts in Endocrinology and Metabolism, pp 57. Eds LI Rose \& RL Lavine. New York: Grune and Stratton, 1977.

7 Burke CW \& Beardwell CG. Cushing's syndrome: an evaluation of the clinical usefulness of urinary free cortisol and other steroid measurements in diagnosis. Quarterly Journal of Medicine 197342 175-204.

8 Eddy RL, Jones AL, Gilliland PF, Ibarra JD, Thompson JQ, MacMurray FR et al. Cushing's syndrome: a prospective study of diagnostic methods. American Journal of Medicine 197355621 630.
9 West P. Application of a modified Cortipac procedure for the estimation of urinary free cortisol in various clinical situations. Journal of Clinical Pathology 198033 89-92.

10 Gilliland J \& Phillips PJ. Urinary free cortisol excretion and renal function. Journal of Clinical Pathology 197831 671-672.

11 Ogunlesi AO, Akanji AO, Kadiri S \& Osotimehin B. Uraemia and adrenocortical function in Nigerian subjects. African Journal of Medical Sciences $19901943-48$.

12 Wallace EZ, Rosman P, Toshav N, Sacerdote A \& Balthazar A. Pituitary adrenocortical function in chronic renal failure. Journal of Clinical Endocrinology and Metabolism 198050 46-51.

13 Bacon GE, Kenny FM, Mardaugh HV, Richards C et al. Prolonged serum half-life of cortisol in chronic renal failure. Johns Hopkins Medical Journal 1973132 127-131.

14 Vanluchene E, Vandekerckhove D, Thiery M \& Van Holder R. Changes in cortisol metabolism in various physiological and pathological situations. Annales d'Endocrinologie $1981 \quad 42$ 284-285.

15 Schoneshofer M, Weber B, Oelkers W, Nahoul K \& Mantero F. Measurement of urinary free $20 \alpha$-dihydrocortisol in biochemical diagnosis of chronic hypercorticoidism. Clinical Chemistry 1986 32 808-810.

16 Schoneshofer M, Weber B \& Nigam S. Increased urinary excretion of free $20 \alpha$ - and $20 \beta$-dihydrocortisol in a hypercortisolemic but hypocortisoluric patient with Cushing's disease. Clinical Chemistry $198329385-389$.

17 Voccia E, Saenger P, Peterson RE, Rauh W, Gottesdiener K, Levine L \& New MI. 6 $\beta$-Hydroxycortisol excretion in hypercortisolemic states. Journal of Clinical Endocrinology and Metabolism $197948467-471$.

18 Bright GM. Corticosteroid-binding globulin influences kinetic parameters of plasma cortisol transport and clearance. Journal of Clinical Endocrinology and Metabolism 199580 770-775.

Received 7 October 1998

Accepted 7 October 1998 